\title{
A construção social da adoção e seu processo de vinculação parental
}

A social construction of adoption and its parental vinculation process

\author{
Pâmela Giovana Missias Moreira ${ }^{\dagger}$, Thais Leite Reis ${ }^{\text {** }}$
}

Como citar esse artigo. Moreira, P.G. M.; Reis, T.L. A construção social da adoção e seu processo de vinculação parental. Revista Mosaico, v.11, n.2, p. $124-130,2020$.

Nota da Editora. Os artigos publicados na Revista Mosaico são de responsabilidade de seus autores. As informações neles contidas, bem como as opiniões emitidas, não representam pontos de vista da Universidade de Vassouras ou de suas Revistas.

\begin{abstract}
Resumo
Desde tempos remotos, a adoção esteve presente de várias maneiras em diversas civilizações. Com isso, foram analisadas questões voltadas ao âmbito histórico do ato de adotar, desde as primeiras Leis encontradas no Código de Hammurábi, no século XVIII a.C., até as Leis vigentes que estabeleceram o Cadastro Nacional de Adoção. A adoção será definida e entendida como uma forma de filiação construída a partir, principalmente, da subjetividade. Foram pontuados os motivos que levam uma pessoa a dar início num processo de adoção e seus possíveis mitos e crenças. O presente artigo tem como objetivo refletir acerca das expectativas e medos dos pais adotivos frente à realidade da adoção sendo produzido a partir de pesquisas bibliográficas. Conclui-se, portanto, que deve ser feita uma reflexão sobre a importância do acolhimento dessa demanda, muitas vezes trazidas pelos pais e suas repercussões na convivência familiar que poderão ser construídos a partir dos laços afetivos.

Palavras-chave: Adoção; Imaginário coletivo; Vínculos filiais.
\end{abstract} prática recente, a mesma já vem sendo feita desde o século XVIII a.C., quando foi criado o Código de Hammurábi (CÓDIGO DE HAMMURÁBI, séc. XVIII a.C.), que trazia algumas das primeiras leis referentes à adoção. Após o Código de Hammurábi, temos o direito Romano, quando as pessoas passaram a adotar quando não podiam gerar um filho por vias naturais, fazendo com que sua geração e os cultos domésticos não se encerrassem (COULANGES, 2006).

Ademais, em 1805, no direito moderno, o imperador Napoleão, por interesses próprios em adotar Eugene Bauharnais, e como consequências das guerras que deixavam muitas crianças órfãs, fez renascer o procedimento da adoção (LOPES, 2008).

No Brasil, com a Lei 3.071/1916 que instituiu o Código Civil dos Estados Unidos no país, havia somente a possibilidade da adoção para pessoas que tivessem no mínimo 50 anos de idade, sem filhos legítimos ou legitimados. Prevendo, também, que ninguém pudesse ser adotado por mais de uma pessoa. Com a Lei 3.133/57, a idade mínima para a adoção passou a ser 30 anos, sendo solteiro ou casado, tendo ou não filhos legítimos.

No cenário atual, por meio da Constituição Federativa do Brasil de 1988, é vedado que as crianças e adolescentes adotados sejam tratados de maneira diferenciada dos filhos biológicos, garantindo a igualdade entre os filhos de laços sanguíneos e os de laços afetivos.

Com a implementação do Estatuto da Criança

\footnotetext{
Afiliação dos autores:

${ }^{\dagger}$ Graduanda de Psicologia, Universidade de Vassouras, Vassouras, RJ, Brasil.

\$ Especialista em jurídica, Universidade de Vassouras, Vassouras, RJ, Brasil.
}

* Email de correspondência: pamelamoreira2014@outlook.com 
e do Adolescente (ECA) de 1990, houve o princípio da doutrina de proteção integral, resultado da Convenção Internacional sobre os Direitos das Crianças de 1989. Essa convenção tinha como meta incentivar alguns países à implementação do desenvolvimento pleno e atencioso de suas crianças, favorecendo o seu crescimento num ambiente familiar.

Em 2002, continuando com o Novo Código Civil, houve a reafirmação de quase todos os requisitos colocados no ECA. Posteriormente, foi criada a Lei 12.010/09, chamada Nova Lei da Adoção, revogando alguns artigos do ECA e ampliando o conceito de família.

A partir dessa contextualização, foi feita uma redefinição, segundo Levinzon (2016), sobre a adoção e os motivos que levam uma pessoa ou casal a desejarem ou optarem por um processo de adoção (como a infertilidade e o desejo de ajudar ao próximo) bem como os possíveis mitos e expectativas dos pais em relação aos filhos na adoção.

$\mathrm{O}$ artigo foi produzido a partir de levantamentos de pesquisas bibliográficas, que foram desenvolvidas algumas reflexões sobre a prática e o cenário da adoção no país, tendo como objetivo principal a compreensão do mundo subjetivo, as crenças e os medos presentes nesses pais.

\section{Uma breve visão histórica da adoção}

O Código de Hammurábi, homenagem ao rei da Babilônia, Hammurábi, que viveu no século XVIII a.C., foi um dos primeiros Códigos a criar Leis voltadas para o ato da adoção. Segundo esse código, no artigo 185, se alguém desse o seu nome a uma criança e a criasse como seu filho, ela não mais poderia ser requerida pelos pais biológicos, pois estaria burlando o princípio da justiça elementar. Contudo, se o pai adotivo não contribuísse para o seu desenvolvimento, esse infante poderia voltar à casa do pai de sangue (CÓDIGO DE HAMMURÁBI, séc. XVIII a.C.).

A adoção, na época, era vista em caráter contratual e só poderia ser anulada caso a criança se revoltasse de alguma forma contra os pais adotivos, se estes não o ensinassem nenhum ofício ou se não o considerassem mais como filho por terem tido outros de ordem natural (CÓDIGO DE HAMMURÁBI, sec. XVIII a.C.).

Nos artigos 190 e 191 desse mesmo Código, começou-se a pensar numa possível igualdade no tratamento entre o filho biológico e o filho adotivo, sendo preconizado que se o pai adotivo tivesse um filho biológico e não mais considerasse o adotado, deveria distribuir para ele seu patrimônio permanecendo sem nada. O Código de Hammurábi foi feito numa época na qual a juridicidade estava nas mãos de pessoas que se sentiam ofendidas de alguma forma e não nas mãos da justiça e, por isso, a ofensa gerava obrigatoriamente uma reação (CÓDIGO DE HAMMURÁBI, séc. XVIII a.C.).

Em Roma, o Direito Romano, que foi fundado em 753 a.C., perpetuou até a morte do imperador Justiniano, em 565 d. C. Os romanos eram pessoas muito religiosas e acreditavam que para conseguirem uma felicidade após a morte dependeria do culto fúnebre feito pelos seus descendentes além, é claro, de suas atitudes em vida (COULANGES, 2006). Naquela época não ter filhos era vergonhoso e significava ter que parar com a geração. Temendo o fim de várias gerações pela impossibilidade de gerar um filho, começou-se a abrir espaço para a adoção como sendo o último recurso a ser solicitado, no caso de todas as opções já terem sido exploradas e descartadas. Assim, a adoção entraria como forma de salvação da família e parte dos cultos sagrados (COULANGES, 2006).

Quando a adoção se fazia necessário, antes de qualquer coisa deveria inserir o filho nas leis sagradas ensinando os cultos domésticos e aproximando-o de seus penates estáticos, deuses do lar. Por isso, a adoção era realizada numa cerimônia sagrada, semelhante à cerimônia que ocorria com o nascimento de um filho natural. Dessa forma, simbolizava que o filho adotivo estava sendo aceito na religião e na nova família. Assim, ele deveria renunciar ao culto de sua antiga família, pois de acordo com a crença, o mesmo homem não poderia honrar duas espécies diferentes de antepassados (COULANGES, 2006).

Para o Direito Romano, o filho adotivo não mais poderia voltar à casa de sua família biológica se não lhes desse um filho. A lei permitia que, somente quando o filho adotivo tivesse um filho, este ficasse na casa de sua família adotiva para que a descendência e os cultos domésticos não acabassem. Assim, ele poderia voltar à sua família de origem, mas deveria romper todos os laços que o ligassem ao filho (COULANGES, 2006).

Na França, em 1805, o berço do Direito Moderno, Napoleão fez renascer o procedimento da adoção pelos interesses próprios de adotar Eugene Bauharnais. Além do próprio interesse, Napoleão visou também os filhos de militares que ficaram órfãos, os chamados "pupilos na Nação." (LOPES, 2008). Com a Lei de 17 de julho de 1927 , os franceses passaram a adotar esses órfãos cujos pais morreram no período da Grande Guerra (1914 a 1918). A adoção tinha um caráter de caridade e somente no ano de 1966 abandonou-se essa "legitimação adotiva" empregando a "adoção plena", em que o adotado agora é desconectado completamente de sua antiga família passando a ter condição de filho legítimo da família adotante (LOPES, 2008).

No Brasil, entrou em vigor a Lei 3.071 de 1916, que instituiu o Código Civil dos Estados Unidos no Brasil (LOPES, 2008). Com relação à adoção, o Código Civil só possibilitava a adoção se o adotante 
tivesse 50 anos de idade e não tivesse filhos legítimos ou legitimados. Ainda era necessário ter 18 anos a mais que o adotado. $O$ código também previa que ninguém fosse adotado por mais de uma pessoa, a menos que fossem marido e mulher (LOPES, 2008). No artigo 375, diz que a adoção deveria ser concretizada por uma escritura pública, tirando o pátrio poder do pai biológico para o pai adotivo. $\mathrm{O}$ vínculo da adoção poderia ser rompido quando cessasse a interdição com a maioridade e quando o filho adotivo cometesse ingratidão contra o adotante (LOPES, 2008). Com a Lei 3.133/57, o Código Civil foi revogado em 5 artigos. A partir disso, a idade mínima do adotante passou a ser de 30 anos, sendo solteiro ou casado, porém, se casado, o matrimônio deveria ter, no mínimo, cinco anos para poder adotar (LOPES, 2008). $\mathrm{O}$ adotante deveria ter 16 anos a mais que o adotado não necessitando mais a inexistência de filhos biológicos. Nos artigos 377 e 378 do Código Civil a adoção não garantia o direito à herança e que, em relação aos pais biológicos, a única coisa que se extinguia era a perda do pátrio poder, que passava do pai natural para o pai adotivo e não os vínculos familiares naturais. Ainda no Código Civil, o filho adotado não possuía os mesmos direitos que os filhos biológicos. Os adotados poderiam possuir apenas metade do que era direito do filho de sangue. Os filhos por via da adoção eram tratados como se fossem fruto de um empréstimo, sendo assim o direito sobre ele poderia ser transferido. Mesmo assim, com essas mudanças, o número de adoção aumentou de forma significativa na época (LOPES, 2008).

Ao que foi possível perceber com esse breve recorte histórico, a adoção geralmente esteve vinculada a uma necessidade do adotante; ora de cunho religioso, para dar continuidade a família, ora como forma caritativa, mas de modo que a criança tivesse que servir fielmente aos costumes dos adotados. Desse modo, o maior interesse que parecia imperar desde então eram dos pais adotivos e não o da criança ter uma nova família.

\section{A atual política da adoção} 227 diz que:

Na Constituição Federal de 1988, no seu artigo

É dever da família, da sociedade e do Estado assegurar à criança e ao adolescente, com absoluta prioridade, o direito à vida, à saúde, à alimentação, à educação, ao lazer, à profissionalização, à cultura, à dignidade, ao respeito, à liberdade e à convivência familiar e comunitária, além de colocá-los a salvo de toda forma denegligência, discriminação, exploração, violência, crueldade e opressão (CF, 1988).

O artigo 227, inciso VI da Constituição de 1988, proíbe a marginalização de crianças e adolescentes adotados referente à diferenciação em relação aos laços sanguíneos. Concomitantemente, a garantia de igualdade entre o filho adotado e o filho biológico segundo o Código Civil (1916) cai em desuso. Agora, há o rompimento definitivo com a família biológica e a criança ou adolescente adotado não possui mais direitos à herança de sua família de origem. Antes, o adotado era visto como um objeto que a família adotiva poderia devolver a qualquer momento, mas com a nova Constituição (1988) a adoção torna-se irrevogável, deixando de ter um caráter contratual, feita por escritura pública e passando a ter a participação do poder público através do judiciário. Sendo assim, atualmente, os casos de devolução após a adoção são entendidos como abandono de incapaz aplicando, então, toda a sanção prevista no ECA, como a destituição do poder familiar e multa administrativa.

A Convenção Internacional sobre os Direitos das Crianças (1989), tratado internacional de direitos humanos, possibilitou a implementação do Estatuto da Criança e do Adolescente (1990) por meio do princípio da proteção integral, no qual as crianças e adolescentes agora são vistos como sujeitos de direitos e não em situação irregular conforme previa o Código de Menores de 1979. Essa legislação ainda estigmatizava as crianças e adolescentes abandonados e "delinquentes" entendendo o controle como modo de cuidado. Nos espaços em que eram depositados, utilizavam métodos correcionais de punição como forma de educação de comportamentos inadequados enfatizando a institucionalização e o rompimento de vínculos comunitário e familiar de crianças e adolescentes como forma de "proteção" à infância (WEBER, 2015).

Segundo o Estatuto da Criança e do Adolescente (1990), só pessoas a partir de 21 anos de idade poderiam adotar. Assim, se um casal desejasse a adoção bastava que um dos dois possuísse os 21 anos completos. Contudo, ainda se faz necessário que o adotante possua 16 anos a mais que o adotado (BRAUNER; ALDROVANDI, 2010).

Em 2002, com o Novo Código Civil, a maioridade civil passa a ser 18 anos de idade e reafirma quase todos os requisitos colocados no Estatuto da Criança e do Adolescente (1990), mantendo também a diferença de 16 anos de idade entre o adotante e o adotado (LOPES, 2008).

Em 2009, com a Lei $n^{\circ} 12.010$, a chamada Nova Lei da Adoção, revoga alguns artigos do Estatuto da Criança e do Adolescente e reforça que a criança ou adolescente permaneça com suas famílias de origem e, quando não for possível, continuem juntos aos parentes próximos (BRAUNER; ALDROVANDI, 2010). A lei contempla as mulheres grávidas que desejam entregar seus filhos para a adoção, as quais devem ser obrigatoriamente encaminhadas à Vara de Justiça da Infância e Juventude, não sendo caracterizado como abandono materno. E ainda reafirma o que consta no Código Civil de 2002 referente à idade mínima de 18 
anos para adoção e sobre a diferença de 16 anos entre o adotado e o adotante (BRAUNER; ALDROVANDI, 2010).

Com os marcos legais vigentes, observa-se uma maior preocupação do Estado com a proteção da criança e do adolescente vislumbrando interesses que favoreçam um ambiente com desenvolvimento saudável e os direitos fundamentais previstos na Constituição Federal (1988), tais como liberdade, educação, segurança, saúde etc.

\section{Entendendo o processo de adoção}

A pessoa que decide iniciar o processo de adoção precisa dar entrada com o pedido na Vara de Infância e Juventude do Tribunal de Justiça, participar das entrevistas, ser inscrito no Cadastro Nacional de Adoção e realizar encontros com os grupos de apoio aos habilitados para a adoção. Após esses procedimentos, e com a habilitação concluída, a pessoa espera a chegada do filho de acordo com o perfil solicitado (RIBEIRO, 2013).

Vimos que o conceito de adoção vem variando durante o passar dos tempos, tanto de maneira legal, quanto de maneira informal. Como já foi mencionado na história da adoção, as leis favoreceram uma discriminação entre os filhos adotivos e os filhos biológicos, o que permeia na sociedade até os dias atuais. Com isso, a adoção é vista como um processo de filiação de "segunda categoria", pois enfatiza os laços sanguíneos na imaginação coletiva como a primeira forma legítima de compor o vínculo familiar (WEBER, 2015).

Segundo Levinzon (2006), adoção é a criação de vínculos parentais que não estão ligados aos vínculos biológicos. A adoção proporciona um lar a crianças e adolescentes que, por algum motivo, como a perda do poder familiar, por abuso sexual intrafamiliar, não puderam permanecer em suas famílias de origem devido a não terem seus direitos garantidos. Também possibilita que famílias que não desejam gerar ou não puderam gerar um filho desempenhem um papel parental através da criação de vínculos filiais afetivos.

Portanto, o processo de adoção é composto por subjetividades já que, para os pais adotivos a adoção será uma possibilidade de exercer essa função parental. O desejo dos pais de construírem vínculos é real, mas é necessário que se compreenda que não é simplesmente um direito. Somente a criança possui o direito de convivência familiar com proteção e resguardo, como prevê o Estatuto da Criança e do Adolescente, direito esse que foi conquistado tardiamente, como declara Weber (2015).

Os motivos que levam as pessoas a participarem de um processo de adoção variam desde infertilidade, perda de um filho ou desejo de ajudar o próximo ao medo de uma gravidez (LEVINZON, 2006). Por isso, para nos referirmos à adoção é importante levarmos em consideração a motivação dos candidatos, bem como seus possíveis mitos permeados (LEVINZON, 2006). Para isso, seus sentimentos de perda, incapacidade ou fracassos necessitam ser trabalhados antes mesmo do começo do estágio de convivência como filho.

Quando a habilitação não ocorre, como é prevista na lei, por meio de orientações, informações e reflexões a respeito das condições inerentes à adoção, o convívio familiar pode ser conflituoso, pois os pais podem depositar na criança ou no adolescente seus medos, sendo super protetivos, por exemplo (LEVINZON, 2006). Assim, o espaço de convivência que deveria ser de construção mútua pode ser idealizado pelos pais que por vezes se sentem frustrados por não serem correspondidos. Desse modo, por não terem suas expectativas atingidas, os pais podem devolver os filhos (LEVINZON, 2006).

\section{O cadastro nacional de adoção e suas repercusões}

De acordo com o Cadastro Nacional de Justiça (CNJ), existem 5.021 crianças a espera da adoção no Brasil e aproximadamente 45.987 mil candidatos que estão atualmente habilitados para a adoção ${ }^{1}$. Contudo, a questão perpassa pelo perfil rígido da escolha do filho, assim sendo, a idade da criança para adoção compreende geralmente de 0 a 3 anos, sem irmãos, cor branca e saudável, o que dificulta ainda mais o processo de adoção (BRAGANÇA; PEREIRA JUNIOR, 2015).

Segundo o Cadastro Nacional de Adoção (CNA, 2008), a adoção tardia de crianças não corresponde ao perfil desejado na maioria dos habilitados, ou seja, menos de 50\% querem adotar crianças e adolescentes com idade superior a 7 anos de idade. Todavia, $80 \%$ de acolhidos compreende a faixa etária de 04 a 17 anos de idade. No Estado do Rio de Janeiro, por exemplo, há cerca de 390 crianças e adolescentes disponíveis para a adoção, mas a maioria pertence a grupos de irmãos e de cor negra ${ }^{2}$.

De acordo com esses números, refletimos a predominância da criança na primeira infância, pois além da "maior facilidade" em adequá-las ao novo ambiente, existem alguns pais que fantasiam que são biológicas (LEVINZON, 2006). Desse modo, valorizam a semelhança das características físicas da criança evitando a visualização para a sociedade da incapacidade de gerar um filho biológico (PEREIRA, 2012). Com isso, mostra-se que os vínculos genéticos ainda são predominantes nas famílias, o que pode influenciar no tratamento e convivência entre filhos biológicos e adotivos (MAUX; DUTRA, 2010). 
Como vimos, o processo de adoção pode envolver sentimentos e sensações entre os pais, a citar: ansiedade, desejos e medos. Com a chegada de uma criança, que já possui uma história, os pais precisam de coragem para enfrentar o estigma social, seus mitos e suas crenças (LEVINZON, 2006).

Por isso, adotar bebês envolve uma maior facilidade na relação, pois a criança na primeira infância, por mais que seja possuidora de uma história, pode não expressar a falta da família de origem, tendo mais facilidade na adaptação ao ambiente que as crianças e adolescentes da esfera da adoção tardia (LEVINZON, 2016).

Adotar crianças mais velhas e adolescentes, talvez por possuírem um maior entendimento do rompimento de vínculo, podem requerer mais atenção, pois terão consciência de possíveis traumas podendo refletir na adaptação. Todavia, tendem a ser mais independentes, comunicativos, além de já terem o conhecimento sobre a família de origem e sua própria história. A adoção de irmãos pode ser desafiadora, como por exemplo acarretar maior gasto econômico e, às vezes, consideram-se autossuficientes enquanto família, no entanto, podem dar apoio um ao outro nessa nova realidade. Assim, a relação fraterna pode ajudar na superação dos possíveis traumas e na adaptação ao novo contexto familiar (MAGALHÃES, 2014).

$\mathrm{Na}$ verdade, para um bom convívio familiar, independente da idade, é necessário que o habilitado seja sensível a ponto de perceber os sentimentos dessa criança ou adolescente, atentando para o que este traz na "mala" e acolhê-lo. A partir disso, os vínculos podem ser criados e poderá haver um laço de confiança (MAGALHÃES, 2014).

\section{A adoção e a imaginação coletiva}

Como já visto, na adoção, o caminho para se construir uma família com laços filiais é diferente das famílias com os laços obtidos a partir dos vínculos sanguíneos. Nas entrevistas para adoção, serão questionados o desejo de ter um filho por adoção e a própria história de vida do possível habilitado. Assim, percebemos que o primeiro contato dos pais com os filhos possivelmente não será no hospital, como ocorre com os filhos obtidos por vias naturais. No processo de espera, a esperança será o toque de um telefone, em que a qualquer momento poderá estar anunciando a disponibilidade de uma criança que poderá vir repleta de histórias que precisam ser respeitadas (RIBEIRO, 2013).

A convivência familiar por adoção pode apresentar, como em qualquer família consanguínea, conflitos e dificuldades no ambiente (WINNICOTT, 1953/1994). Contudo, algumas peculiaridades só são encontradas em famílias com processo de adoção, pois demandam um maior esforço para a adaptação na nova rotina do que as famílias com vínculos biológicos (LEVINZON, 2016).

A criança ou adolescente adotivo passou por experiências de rompimento de vínculo com a mãe biológica, o que pode ter sido traumático, principalmente dependendo da maneira como se deu essa separação. Segundo Levinzon (2016), o bebê e a mãe possuem uma identificação na qual eles aprendem o ritmo um do outro e acabam por responder às expectativas mútuas. Quando a criança é adotada, essa identificação demanda um esforço bem maior do aparelho psíquico. A criança adotada, aos poucos, vai perdendo o vínculo com a mãe biológica podendo desenvolver um extremo medo de ser abandonada novamente (LEVINZON, 2016).

A marca do abandono e do desamparo podem ficar gravadas na criança. Por isso, quanto menor for a idade da criança adotada, maiores serão as facilidades que terão para refazer os laços afetivos. Portanto, nas adoções tardias, faz-se necessário pensar no desamparo e no sofrimento e realizar um esforço maior para se adaptar aos novos pais, ou seja, à nova família (LEVINZON, 2016).

Os pais adotivos poderão se deparar com desafios a serem enfrentados e superados para uma convivência salutar, por exemplo, seus afetos podem ser testados pelos filhos como uma forma de garantia de um não abandono. No caso da adoção de criança ou adolescente, será necessária uma persistência maior dos pais em acolhê-lo nesses testes de confiança, assim, poderão construir uma relação de vínculo (RAMOS, 2016).

No processo de adoção, as crianças e os adolescentes podem apresentar comportamentos regressivos, atitudes que não correspondem à idade cronológica, à agressividade e à idealização da família de origem. Além disso, os pais precisarão fazer um enfrentamento do estigma social de pessoas que ainda possuem preconceitos voltados para à prática de adoção (WEBER, 2015).

Um medo bastante presente dos pais adotivos é o do filho procurar a família biológica, isso por temerem que os vínculos parentais possam valer mais subjetivamente que os afetivos (MAUX; DUTRA, 2010). Segundo Levinzon (2016), a dinâmica familiar ocorre baseada nas fantasias e angústias do processo de adoção, no qual ficam tecidos os temores e afetos de cada um que constitui a família. Essa fantasia de que o filho pode trocá-los pelos pais biológicos pode gerar, nos pais adotivos, uma vontade de superproteção. (MAUX; DUTRA, 2010)

Compreende-se que, por mais que os pais tenham entendido a função inerente ao poder familiar por meio da adoção, ainda existe uma imaginação coletiva de que mãe é quem gera. Por isso, a fantasia de que os filhos não irão aceitá-los como pais poderá assombrá-los a 
todo instante (LEVY; JONATHAN, 2004).

A teoria do amor materno, em que a mulher já nasce pronta para ser mãe, pode gerar, na figura materna, sentimentos de incapacidade para exercer a função. Contudo, a idealização é uma construção assim como o amor real que também poderá ser produzido baseado no desejo e na vontade de criar novos laços (BADINTER, 1985).

O peso da consanguinidade também é evidenciado no momento da revelação para a criança a respeito da adoção, pois os pais com receio da reação do filho podem alimentar mentiras ou omissão para que a criança acredite no vínculo sanguíneo. Dessa forma, evita-se questionamentos sobre o processo de adoção mascarando os sentimentos de abandono e rejeição (MAUX; DUTRA, 2010).

A restrição de possibilidades na construção da relação de pais e filhos pode gerar alguns conflitos na adaptação da criança com a família, pois muitas vezes os pais idealizam a convivência não avaliando os desafios que, porventura, terão que enfrentar (LEVINZON, 2016). Os pais adotivos, assim como os biológicos, possuem crenças sobre o desenvolvimento de seus filhos causando, possivelmente, inseguranças na educação (BADINTER, 1985).

Então, o processo de adoção não está somente ligado à vontade de construir uma família, mas na aceitação de mudanças da rotina, baseadas na convivência com a criança real (LEVINZON, 2016). A adoção envolve estabelecer os vínculos com a criança, semelhante ao filho biológico que é esperado por nove meses em que a ideia de gerar uma vida e criar laços é construída no processo. No entanto, a criança adotada já vem pronta, por isso o laço afetivo precisa ser criado. A diferença está no modo de espera do filho, pois na adoção não são criados laços e afetos desde o ventre, mas desde a espera, no cadastro. A partir disso, a elaboração dos sentimentos e expectativas dos habilitados é imprescindível para construir as relações de afetos a partir do real e não da imaginação coletiva no que diz respeito à adoção (LEVINZON, 2006).

\section{Considerações Finais}

A adoção é uma forma antiga de filiação socioafetiva, um vínculo de parentesco estabelecido por uma ação jurídica, porém as pessoas, sobretudo as que adotam, podem possuir uma imagem distorcida dos filhos não legítimos, sendo estes marginalizados da convivência familiar ou idealizados sendo depositadas sobre eles suas expectativas.

Assim, o preconceito social com relação à adoção pode gerar nos pais sentimentos como: medo, ansiedade e receio no que diz respeito à perda desse filho, por exemplo, além de criar a fantasia de que os laços sanguíneos que os filhos possuem com a família biológica são suficientes para fazerem com que os abandonem em prol à família sanguínea. Com a alimentação desse imaginário, muitas vezes os pais podem ter dificuldades na educação dos filhos colocando a culpa dos conflitos da convivência e adaptação na criança.

Portanto, para que a adoção seja efetiva devese avaliar, além do desejo de gerar um filho e construir uma família, suas reais motivações.

Sendo assim, é necessário que o processo de adoção ocorra em "mão dupla", no qual não só a criança será adotada, mas também os pais precisam ser adotados por ela, para que esse processo ocorra de maneira satisfatória. E isso será possível, por meio do fortalecimento dos vínculos familiares.

Para além, estão os cuidados com as motivações do habilitado, para que a criança não seja objeto de substituição do filho biológico. Por isso, o luto pelo filho idealizado precisa existir para a ressignificação dessa falta e a possibilidade de uma convivência familiar salutar (HAMAD, 2002).

\section{Nota}

1. Informação fornecida pelo Relatório Estatístico, com a atualização de 2019, do Cadastro Nacional de Adoção (CNA). Disponível em: < http://www. cnj.jus.br/cnanovo/pages/publico/index.jsf> Acesso em: 27 de mar. 2019.

2. Informação fornecida pelo relatório atualizado do Cadastro Nacional de Adoção (CNA).

\section{Referências}

BADINTER, E. Um amor conquistado: o mito do mor materno. Rio de Janeiro: Nova Fronteira, 1985.

BRAUNER, M. C. C.; ALDROVANDI, A. Adoção no Brasil: aspectos evolutivos do Instituto no direito de família. Rio Grande, JURIS, 2010.

BRASIL. Lei Federal n ${ }^{\circ} 10.406,10$ de janeiro de 2002. Código Civil. Brasília, 2002

Presidência da República. Casa Civil. Subchefia para Assuntos Jurídicos. Lei $\mathrm{n}^{\circ}$ 6.697, de 10 de outubro de 1979. Código de Menores. Brasília, 1979

Presidência da República. Casa Civil. Subchefia para Assuntos Jurídicos. Lei nº 8.069, de 13 de julho de 1990 - Estatuto da Criança e do Adolescente, Brasília, 1990.

BRAGANÇA, R. R; PEREIRA JUNIOR, A. A. Crianças institucionalizadas: a demora na adoção. Paraná: UNINGÁ, 2015.

CADASTRO Nacional de Adoção. Brasília, 2010. Disponível em: < http:// www.cnj.jus.br/programas-e-acoes/cadastro-nacional-de-adocao-cna> Acesso em: 27 de mar. 2019.

CÓDIGO DE HAMMURÁBI. Disponível em: <http://culturabrasil.org/zip/ hamurabi.pdf $>$. Acesso em: 24 marc. 2019.

COULANGES, F. A formação da cidade: a cidade antiga. São Paulo: [s.n.], 2006. Disponível em: <http://www.ebooksbrasil.org/eLibris/cidadeantiga. html>. Acesso em: 27 de mar. 2019.

HAMAD, N. A criança adotiva e suas famílias. Rio de Janeiro: Companhia Freud,2002.

LEVINZON, G. K. Adoção e sofrimento psíquico. São Paulo: Psicanálise v.18, 2016 
. A adoção na clínica psicanalítica: o trabalho com os pais adotivos. São Paulo: Mudanças - Psicologia e Saúde, 2006.

LEVY, L.; JONATHAN, E. G. A criança adotada no imaginário social. Porto Alegre: Psico, 2004.

LOPES, C. R. A. Adoção: Aspectos Históricos, Sociais e Jurídicos da Inclusão de Crianças e Adolescentes em Famílias Substitutas. Dissertação de Mestrado - Centro Universitário Salesiano, Lorena, 2008.

MAGALHÃES, F. M. P. A adoção e a sua realidade. 2014. Trabalho de conclusão de curso - Universidade Fernando Pessoa, Porto, 2014.

MAUX, A. A. B.; DUTRA, E. Adoção no Brasil: algumas reflexões. Rio de Janeiro: Estudos e pesquisas em psicologia, 2010.

PEREIRA, P. J. Adoção: realidades e desafios para um Brasil do século XXI. 2012. Dissertação de Doutorado - Universidade de Campinas, Campinas, 2012.

RAMOS, N. R. P. A adoção e o bem-estar da criança: a perspectiva de mães e pais adotantes. Um estudo exploratório. Dissertação de Mestrado Universidade de Évora, Évora, 2016.

RIBEIRO, O. M. L. Adoção: relatos de um assistente social e entrevistas com mães e pais adotivos. São Paulo: Lexia, 2013.

WEBER, L. Pais e filhos por adoção no Brasil: características, expectativas e sentimentos. 10.ed. Curitiba: Juruá, 2015.

WINNICOTT, D. W. (1953). W. R. D. Fairbairn. Explorações psicanalíticas. Porto Alegre: Artmed, 1994 